\title{
Moderate intake of red wine promotes a significant increase of phenolic metabolites in human faeces
}

\author{
Ana Jiménez-Girón*, Irene Muñoz-González, Pedro J. Martín-Álvarez, Begoña Bartolomé \\ and M. Victoria Moreno-Arribas \\ Institute of Food Science Research (CIAL) (CSIC-UAM), Madrid, Spain
}

\begin{abstract}
With the final aim of ascertaining consistent data about the changes of phenolic metabolites in faeces after a regular wine consumption, the present paper compiles the data from two previous human intervention studies: $a$ ) a pilot study $(n=8)$, that compared the ingestion of de-alcoholised red wine $(272 \mathrm{~mL} /$ day $)$, red wine $(272 \mathrm{~mL} /$ day $)$, or gin $(100 \mathrm{~mL} /$ day $)$ during 20 days, and $b$ ) a large trial study ( $n=41,33$ cases and 8 controls), that assessed variability among individuals after the intake of red wine $(250 \mathrm{~mL} / \mathrm{day}, 28$ days). Great coincidence was observed in the main phenolic metabolites identified in the faecal samples from both studies that included benzoic acids, phenols, hippuric acids, phenylacetic acids, phenylpropionic acids, valeric acids, valerolactones and cinnamic acids. However, significant differences $(P<0.05)$ in the total phenolic content between faecal samples before and after the wine intervention was only observed for the large trial study $(358 \pm 270$ and $625 \pm 380 \mu \mathrm{g} / \mathrm{g}$ faeces, corresponding to the mean values before and after the intervention, respectively), emphasizing the large variability in the phenolic-metabolizing gut-microbial capacity among individuals. The overall results confirm that consumption of wine enhances phenolic metabolism, which might have physiological relevancy at the gut level.
\end{abstract}

\section{Introduction}

Recent scientific evidence suggests that dietary polyphenols, including red wine polyphenols, might exert biological effects at the gut level, including antinflamatory activity, modulatory effects on the gut microbiota composition, and interaction with cells, among others. However, these health benefits derived from moderate consumption of wine and other foods rich in polyphenols seem to be due to the metabolites formed during its passage among the gastrointestinal tract, rather than molecular forms originally present in food [1]. It is assumed that the major transforma-

*Corresponding author: Ana Jiménez-Girón, Institute of Food Science Research (CIAL) (CSIC-UAM), C/Nicolás Cabrera, 9, 28049, Madrid, Spain. Tel.: +34 910017900; E-mail: a.jimenez. giron@csic.es. tions of polyphenols in the human body are due to the colonic microbiota whose growth and metabolism could be also modulated by the phenolic metabolites, constituting what is named as a 'two-way interaction' between wine polyphenols and human microbiota [2]. Several authors have used in vitro models that simulate the conditions of the gastrointestinal tract in order to evaluate the metabolism of polyphenols by gut bacteria and also to assess the impact of the polyphenols and/or their metabolites on the growth and metabolic activity of gut microbiota [3-6]. However, human intervention studies are needed to get a deeper understanding on the effects of a moderate wine consumption, and also to take into account the variability of the human microbiota among individuals.

With the final aim of evaluating the potential biological effects of a moderate wine consumption on human microbiota and the phenolic metabolism involved, two 
intervention studies involving healthy volunteers have been carried out. Firstly, a pilot study $(n=8)$ was performed in order to evaluate the effect of alcohol and polyphenols content on the colonic microbiota modulation, and to determine the phenolic metabolites profile in faeces [7]. Secondly, a large trial study was realized considering a more relevant number of volunteers $(n=41)$ in order to assess differences in the phenolic-metabolizing activity among individuals [8]. In the present paper, we have accomplished results from both studies and have drawn final conclusions about the changes in the phenolic metabolite profile of faeces after the consumption of red wine.

\section{Material and methods}

\subsection{Red wines}

A young Merlot red wine (Penedês appellation, Spain) with a total polyphenol content of $798 \mathrm{mg}$ of gallic acid/L was used for the pilot study [7]. For the large trial study, a young Pinot Noir red wine (Penedês appellation, Spain) selected for its high phenolic content (total polyphenol content $=1758 \mathrm{mg}$ of gallic acid $/ \mathrm{L}$ ) was used. Both wines were kindly provided by Bodegas Miguel Torres SA (Catalonia, Spain).

\subsection{Design of the intervention studies}

The pilot study $(n=8)$ was a randomized, crossover, controlled intervention study that was divided into 4 consecutive periods: an initial washout period of 15 days (baseline) during which the volunteers did not consume any alcohol or red wine, followed by 3 consecutive periods of 20 days during which the participants drank only de-alcoholised red wine $(272 \mathrm{~mL} /$ day $)$, red wine $(272 \mathrm{~mL} /$ day $)$, or gin (100 mL/day) (Fig. 1). The large trial study was a randomized and controlled intervention study that only consisted in the moderate consumption of a young red wine by healthy volunteers $(n=41,33$ cases and 8 controls). The study was divided into 2 consecutive periods: a washout period (14 days) followed by a 28 days period during which the volunteers drank $250 \mathrm{~mL} /$ day of red wine, divided into 2 doses (Fig. 1). During both studies, participants maintained the restriction of drinking any other alcoholic beverages and followed a low- polyphenols diet. These studies were carried out according to the rules and approval of the Bioethics committee.

\subsection{Preparation of faecal solutions}

Each volunteer provided a first baseline faecal sample after the washout period and a sample at the end of each intake period. These samples were stored at $-80^{\circ} \mathrm{C}$ awaiting analysis. For preparation of faecal solutions, samples were thawed at room temperature and weighted $(1.0 \mathrm{~g})$ in $15 \mathrm{~mL}$ sterile conical tubes. $10 \mathrm{~mL}$ of sterile saline solution $(\mathrm{NaCl} 0.9 \%$, Fresenius Kabi, Spain) was added, vorterex and centrifuged (10 min, $10000 \mathrm{rpm}, 4^{\circ} \mathrm{C}$ ) two times. The supernatant (faecal solution) was filtered $(0.22 \mu \mathrm{m})$ and diluted with acetonitrile ( $1: 4, \mathrm{v} / \mathrm{v}$, acetonitrile/faecal solution). $2.0 \mu \mathrm{L}$ of sample were injected into the chromatographic system.

\subsection{Analysis of phenolic metabolites}

Faecal solutions were analysed by an UPLCESI-MS/MS method validated for the screening of more than 60 microbial derived phenolic metabolites, including phenols, and mandelic, benzoic, hippuric, phenylacetic, phenylpropionic, valeric and cinnamic acids [7]. Some improvements in detectability and quantification of phenolic metabolites by UPLC-ESIMS/MS were further achieved by using an internal standard (4-hydroxybenzoic 2,3,5,6- $\mathrm{d}_{4}$ acid) [8].

\section{Results and discussion}

Table 1 ensembles the phenolic metabolites determined in the faeces before and after the wine intake from both, pilot and large trial, studies. In the pilot study, 22 phenolic metabolites were detected, comprising benzoic acids, phenols, hippuric acids, phenylacetic acids, phenylpropionic acids, valeric acids, valerolactones and cinnamic acids. These same metabolites plus other 13 compounds (making a total of 35 metabolites) were found in the faecal samples from the large trial study. However, alcohol seemed not to influence the formation of microbial phenolic metabolites [7] or the composition of the colonic microbiota [9]. Differences in the number of the metabolites determined were attributed either to the improvements made 
Pilot study (8 volunteers)

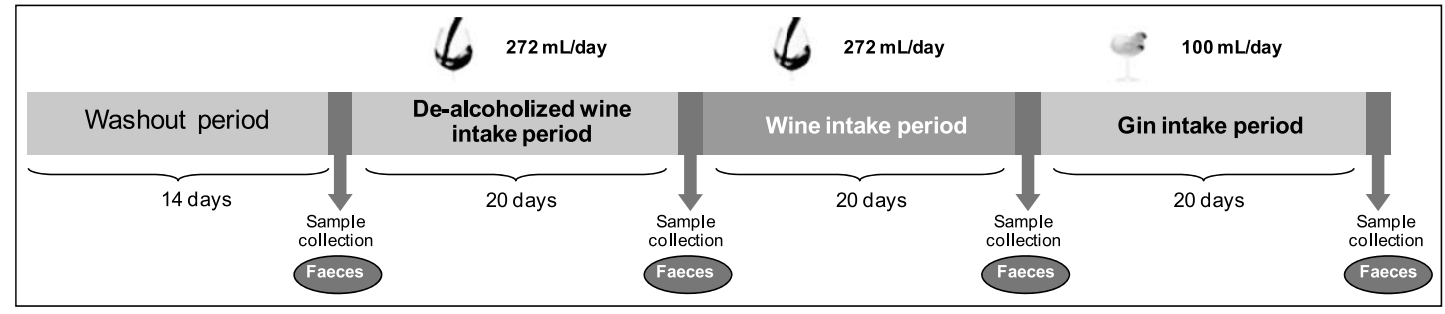

Large trial study (33 volunteers)

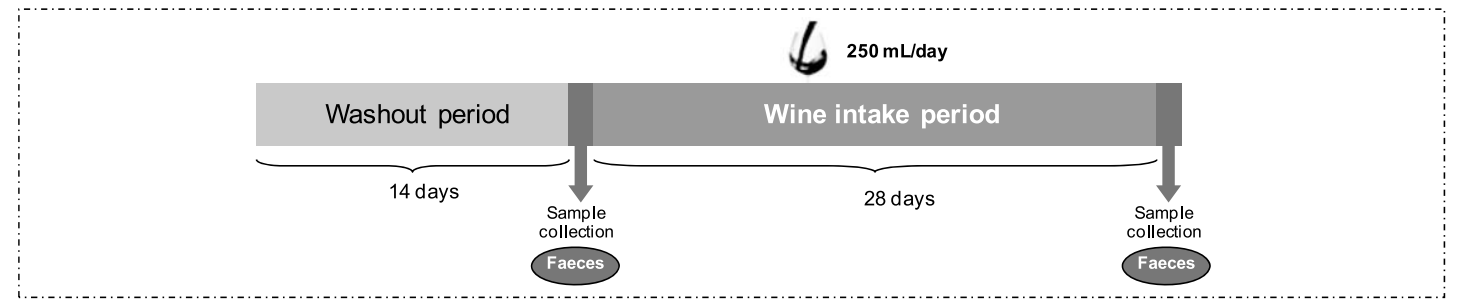

Large trial study (8 control volunteers)

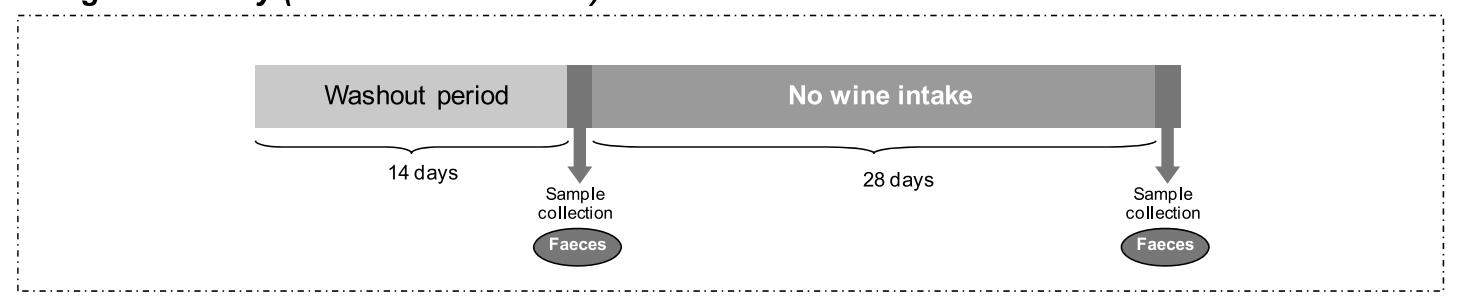

Fig. 1. Schemes of the wine intervention studies.

on the method to enhance its sensitivity, and/or to the higher phenolic content of the wine used (798 and $1758 \mathrm{mg}$ of gallic acid/L in the pilot and large studies, respectively). No detectable amounts of the phenolic compounds presented in the wine (anthocyanins, flavan-3-ols, flavonols or stilbenes) were found in the faecal samples in none of both studies, indicating that they were completely metabolized during its passage through the gastrointestinal tract.

Among the microbial metabolites, benzoic, phenylacetic, 3-phenylpropionic and 4-hydroxy-5-phenylvaleric acids were the most abundant phenolic metabolites at baseline (before wine intake) found in both intervention studies (data not shown). The content of phenolic compounds at baseline obtained in our studies were included within the concentration ranges previously reported in literature [10-15], in spite of the differences in methodology, number of volunteers, and sample preparation among studies. Nevertheless, it is necessary to point out the high inter-individual variability observed in the concentrations of faecal phenolic metabolites within each study, which evidences the difficulty in establishing reference values and the importance of carrying out these studies with a large group of volunteers, under controlled diets, in order to obtain reliable and consistent conclusions.

The $t$-test for dependent samples and its corresponding non-parametric Wilcoxon matched-pairs test were realized to evaluate differences in the content of phenolic acid metabolites in faeces before and after the wine intervention period for both studies (Table 1). In the pilot study (8 volunteers), out of the 22 phenolic metabolites identified in the faecal samples, 8 compounds (mainly benzoic acids) showed statistically significant increases $(P<0.05)$ after the wine intake period, whereas no significant differences $(P>0.05)$ were found in the total phenolic metabolites content $(119 \pm 34 \mu \mathrm{g} / \mathrm{g}$ faeces and $192 \pm 126 \mu \mathrm{g} / \mathrm{g}$ faeces before and after wine intervention). On the other hand, in the large trial study 
Table 1

Phenolic metabolites quantified in faeces before and after the wine intervention period in a pilot study ( 8 volunteers) and in a large trial study (33 volunteers)

\begin{tabular}{|c|c|c|c|c|}
\hline \multirow[b]{2}{*}{ Compound } & \multicolumn{2}{|c|}{ Pilot study } & \multicolumn{2}{|c|}{ Large trial study } \\
\hline & Before & After & Before & After \\
\hline \multicolumn{5}{|l|}{ Mandelic acids } \\
\hline 3-Hydroxymandelic acid & & & + & + \\
\hline \multicolumn{5}{|l|}{ Benzoic acids } \\
\hline Gallic acid & & + & + & + \\
\hline 3,5-Dihydroxybenzoic acid & + & $+*$ & + & $+*$ \\
\hline Protocatechuic acid & + & $+^{*}$ & + & $+^{*}$ \\
\hline 3-O-Methylgallic acid & & $+*$ & + & $+*$ \\
\hline 4-Hydroxybenzoic acid & + & + & + & + \\
\hline 4-O-Methylgallic acid & & & + & + \\
\hline 3-Hydroxybenzoic acid & + & + & + & + \\
\hline Vanillic acid & + & $+^{*}$ & + & $+*$ \\
\hline Syringic acid & & $+^{*}$ & + & $+^{*}$ \\
\hline Benzoic acid & + & + & + & + \\
\hline Salicylic acid & + & + & + & + \\
\hline \multicolumn{5}{|l|}{ Phenols } \\
\hline Catechol/Pyrocatechol & & & + & + \\
\hline 4-Methylcatechol & & & + & + \\
\hline \multicolumn{5}{|l|}{ Hippuric acids } \\
\hline 4-Hydroxyhippuric acid & & & + & + \\
\hline \multicolumn{5}{|l|}{ Phenylacetic acids } \\
\hline 3,4-Dihydroxyphenylacetic acid & & & + & + \\
\hline 4-Hydroxyphenylacetic acid & + & + & + & + \\
\hline 3-Hydroxyphenylacetic acid & + & + & + & + \\
\hline 4-Hydroxy-3-methoxyphenylacetic acid & & & + & + \\
\hline Phenylacetic acid & + & + & + & + \\
\hline \multicolumn{5}{|l|}{ Phenylpropionic acids } \\
\hline 3-(3', $4^{\prime}$-Dihydroxyphenyl)-propionic acid & + & + & + & + \\
\hline 3-(4'-Hydroxyphenyl)-propionic acid & & & + & + \\
\hline 3-(3'-Hydroxyphenyl)-propionic acid & + & + & + & + \\
\hline 3-Phenylpropionic acid & + & $+^{*}$ & + & $+*$ \\
\hline \multicolumn{5}{|l|}{ Valeric acids } \\
\hline 4-Hydroxy-5-(3',4'-dihydroxyphenyl)-valeric acid & & + & + & $+*$ \\
\hline 4-Hydroxy-5-(3'-hydroxyphenyl)-valeric acid & + & + & + & + \\
\hline 4-Hydroxy-5-(phenyl)-valeric acid & + & $+^{*}$ & + & $+*$ \\
\hline \multicolumn{5}{|l|}{ Valerolactones } \\
\hline 5 - $\left(3^{\prime}, 4^{\prime}\right.$, -dihydroxyphenyl $)-\gamma$-valerolactone & & & + & + \\
\hline 5 -(3'-hydroxyphenyl)- $\gamma$-valerolactone & & & & $+^{*}$ \\
\hline 5 -(4'-hydroxyphenyl)- $\gamma$-valerolactone & & & + & + \\
\hline \multicolumn{5}{|l|}{ Cinnamic acids } \\
\hline Caffeic acid & + & + & + & + \\
\hline p-Coumaric acid & + & $+^{*}$ & + & + \\
\hline m-Coumaric acid & & & + & + \\
\hline Ferulic acid & + & + & + & + \\
\hline Isoferulic acid & & & + & + \\
\hline
\end{tabular}

* Mean values significantly different from baseline concentration $(P<0.05)$.

(33 volunteers), out of the 35 phenolic metabolites identified, 9 phenolic metabolites (mainly benzoic and 4-hydroxyvaleric acids) showed statistically significant increases after the wine intake period. Metabolites significantly changing after the red wine interventions mainly come from the catabolism of both flavan-3-ols and anthocyanins, the major flavonoids in red wine. Moreover, the total phenolic metabolites content was significantly higher $(P<0.05)$ in the samples after the wine intake $(625 \pm 380 \mu \mathrm{g} / \mathrm{g}$ faeces $)$ in comparison to 

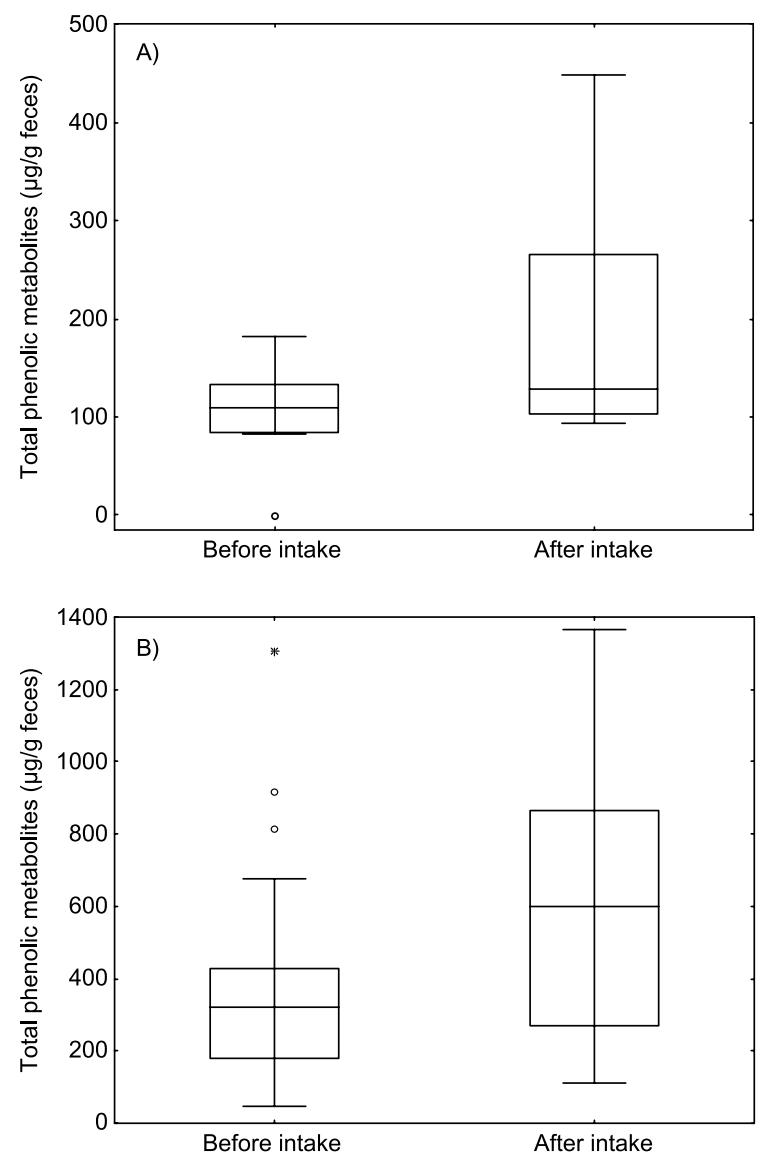

Fig. 2. Box and whiskers plots (-median, 25th-75th percentiles, I non-outlier range, $O$ outliers and 米 extremes) of the total phenolic metabolites in faeces before and after wine intake obtained in: A) the pilot study ( 8 volunteers); and B) the large trial study (33 volunteers).

the samples before $(358 \pm 270 \mu \mathrm{g} / \mathrm{g}$ faeces). To summarize data, Fig. 2 displays the box and whiskers plots (median, 25th and 75th percentiles, non-outlier range, outliers and extremes) of the total phenolic metabolites before and after the red wine intervention for both studies. In general, the 25th-75th percentiles were greater for the samples after the wine intake than samples before the wine intake, indicating that wine polyphenols metabolism enhances inter-individual variability further still.

As other authors have proposed, the human population can be classified into high, moderate and low metabolizers, taking into consideration the levels of a specific phenolic metabolite after an intervention with a source rich in the corresponding precursors $[16,17]$. Thanks to the high number of volunteers considered under the large trial study, an attempt to distribute the volunteers by means of the total phenolic metabo- lite content in faecal solutions was carried out. Thus, three groups could be established according to the total phenolic metabolites content in faeces after wine intervention: $<500 \mu \mathrm{g} / \mathrm{g}$ faeces, $500-1000 \mu \mathrm{g} / \mathrm{g}$ faeces, and $>1000 \mu \mathrm{g} / \mathrm{g}$ faeces [8]. These results suggest a different gut microbial capacity to metabolize wine polyphenols exists among the human population, as observed for polyphenols from other sources.

\section{Conclusions}

In conclusion, these studies reports complementary and valuable data on the basal levels of phenolic metabolites in faeces, which are in accordance to those reported in the literature. Results from both studies indicate that the microbial metabolic profile of faeces is significantly modified after moderate and reg- 
ular intake of red wine polyphenols, which may be related to positive biological effects. Due to the large variability in gut microbiota among individuals, only intervention studies with a large number of volunteers could lead to conclusive results. Our findings support the relevance of the phenolic metabolites in the colon environment, and because of this, the possible gut biological effects associated with moderate wine consumption. From our point to view, more efforts are needed in the identification of wine-polyphenols metabolizing bacteria and in the determination of the bioactive properties of the main metabolites, especially in relation to the microbiota composition.

\section{Acknowledgements}

The authors thank Miguel Torres S.A. winery for providing the red wines. This work was funded by the MINECO (AGL2009-13361-C02-01, AGL201204172-C02-01, and CONSOLIDER INGENIO 2010 (FUN-C-FOOD, CSD2007-063, Projects), and the Comunidad de Madrid (ALIBIRD P2009/AGR-1469 Project). AJ-G and IM-G would like to thank the European Social Fund and Jae-Doc (CSIC) and FPI Programs for their research contracts, respectively.

\section{References}

[1] Monagas M, Urpi-Sarda M, Sánchez-Patán F, Llorach R, Garrido I, Gomez-Cordoves C, Andres-Lacueva C, Bartolome B. Insights into the metabolism and microbial biotransformation of dietary flavan-3-ols and the bioactivity of their metabolites. Food Funct. 2010;(1):233-53.

[2] Requena T, Monagas M, Pozo-Bayón MA, Martín-Álvarez PJ, Bartolomé B, del Campo R, Ávila M, Martínez-Cuesta MC, Peláez C, Moreno-Arribas MV. Perspectives of the potential implications of wine polyphenols on human oral and gut microbiota. Trends Food Sci Tech. 2010;(21): 332-44.

[3] van Dorsten FA, Peters S, Gross G, Gómez-Roldán V, Klinkenberg M, De Vos RC, Vaughan EE, van Duynhoven J, Possemiers S, van de Wiele T, Jacobs DM. Gut microbial metabolism of polyphenols from black tea and red wine/grape juice is source-specific and colon-region dependent. J Agric Food Chem. 2012;(60):11331-42.

[4] Sánchez-Patán F, Cueva C, Monagas M, Walton GE, Gibson GR, Quintanilla-López JE, Lebrón-Aguilar R, Martín-Álvarez $\mathrm{PJ}$, Moreno-Arribas MV, Bartolomé B. In vitro fermentation of a red wine extract by human gut microbiota: Changes in microbial groups and formation of phenolic metabolites. J Agric Food Chem. 2012;(60):2136-47.
[5] Aura AM, Mattila I, Hyotylainen T, Gopalacharyulu P, Cheynier V, Souquet JM, Bes M, Le Bourvellec C, Guyot S, Oresic M. Characterization of microbial metabolism of Syrah grape products in an in vitro colon model using targeted and non-targeted analytical approaches. Eur J Nutr. 2013;(52):83346.

[6] Stalmach A, Edwards CA, Wightman JD, Crozier A. Colonic catabolism of dietary phenolic and polyphenolic compounds from Concord grape juice. Food Funct. 2013;(4):52-62.

[7] Jiménez-Girón A, Queipo-Ortuño MI, Boto-Ordóñez M, Muñoz-González I, Sánchez-Patán F, Monagas M, MartínÁlvarez PJ, Murri M, Tinahones FJ, Andrés-Lacueva C, Bartolomé B, Moreno-Arribas MV. Comparative study of microbial-derived phenolic metabolites in human feces after intake of gin, red wine, and dealcoholized red wine. J Agric Food Chem. 2013;(61):3909-15.

[8] Muñoz-González I, Jiménez-Girón A, Martín-Álvarez, PJ, Bartolomé B, Moreno-Arribas MV. Profiling of microbialderived phenolic metabolites in human feces after moderate red wine intake. J Agric Food Chem. 2013;(61):9470-79.

[9] Queipo-Ortuño I, Boto-Ordoñez M, Murri M, GomezZumaquero JM, Clemente-Postigo M, Estruch R, Cardona Diaz F, Andrés-Lacueva C, Tinahones FJ. Influence of red wine polyphenols and ethanol on the gut microbiota ecology and biochemical biomarkers. Am J Clin Nutr. 2012;(95):1323-34.

[10] Jenner AM, Rafter J, Halliwell B. Human fecal water content of phenolics: The extent of colonic exposure to aromatic compounds. Free Radical Biol Med. 2005;(38):763-72.

[11] Karlsson PC, Huss U, Jenner A, Halliwell B, Bohlin L, Rafter JJ. Human fecal water inhibits COX-2 in colonic HT-29 cells: Role of phenolic compounds. J Nutr. 2005;(135):2343-49.

[12] Knust U, Erben G, Spiegelhalder B, Bartsch H, Owen RW. Identification and quantitation of phenolic compounds in faecal matrix by capillary gas chromatography and nano-electrospray mass spectrometry. Rapid Commun Mass Spectrom. 2006;(20):3119-29.

[13] Gao X, Pujos-Guillot E, Martín JF, Galán P, Juste C, Jia W, Sebedio JL. Metabolite analysis of human fecal water by gas chromatography/mass spectrometry with ethyl chloroformate derivatization. Anal Biochem. 2009;(393):163-75.

[14] Gill CIG, McDougall G, Glidewell S, Stewart D, Shen Q, Tuohy K, Dobbin A, Boyd A, Brown E, Haldar S, Rowland IR. Profiling of phenols in human fecal water after raspberry supplementation. J Agr Food Chem. 2010;(58):10389-95.

[15] Gao X, Pujos-Guillot E, Sebedio JL. Development of a Quantitative Metabolomic Approach to Study Clinical Human Fecal Water Metabolome Based on Trimethylsilylation Derivatization and GC/MS Analysis. Anal Chem. 2010;(82):6447-56.

[16] Bolca S, Possemiers S, Verstraete W, van de Wiele T, Huybrechts I, de Henauw S, Depypere H, Bracke, M. Microbial and dietary factors associated with the equol and 8prenylnaringenin producer phenotypes. Acta Hort. 2009;(848): 235-46.

[17] Truchado P, Larrosa M, García-Conesa MT, Cerdá B, VidalGuevara ML, Tomás-Barberán FA, Espín JC. Strawberry processing does not affect the production and urinary excretion of urolithins, ellagic acid metabolites, in humans. J Agric Food Chem. 2012;(60):5749-54. 